\title{
IV. On the reduction of Mr. Faraday's discoveries in magneto-electric induction to a general law
}

\author{
Rev. William Ritchie LL.D. F.R.S.
}

To cite this article: Rev. William Ritchie LL.D. F.R.S. (1834) IV. On the reduction of Mr. Faraday's discoveries in magneto-electric induction to a general law, Philosophical Magazine Series 3, 4:19, 11-13, DOI: $10.1080 / 14786443408648242$

To link to this article: http://dx.doi.org/10.1080/14786443408648242

册 Published online: 01 Jun 2009.

Submit your article to this journal $₫$

Џ Article views: 4

Q View related articles $₫$ 
IV. On the Reduction of Mr. Faraday's Discoveries in Magneto-Electric Induction to a general Lars. By the Rer. William Ritchie, LL.D., F.R.S., Professor of Natural and Experimental Philosophy in the Royal Institution of Great Britain, and in the University of London.

\section{My Dear Sir,}

\section{To Sir David Breroster.}

$\mathrm{N}$ a lecture which $\mathrm{I}$ had the honour of delivering before 1 the British Association at the Oxford Meeting, I first pointed out, and illustrated by experiment, a general law, which connects together the splendid discoveries made by Mr. Faraday on the subject of magneto-electricity. As one of the most essential parts of science is the reduction of facts to general laws, and as the views which I then developed have only been published in the Abstracts of the Royal Society*, I have ventured to request you to give them a place in your widely extended Journal. I am, my dear Sir, yours truly,

Wm. Ritchie.

The law is founded on the universal principle that action and reaction are equal. Thus, if voltaic electricity induce magnetism under certain arrangements, magnetism will, by similar arrangements, react on a conductor and induce voltaic electricity. Instead of stating the law of magneto-electric induction and then illustrating it by experiment, it will be more instructive to arrive at it by a process of induction.

1. If a piece of soft iron, $\mathrm{NS}$, be made to approach rapidly a voltaic conductor, and at right angles to its direction, the soft iron will be converted into a magnet having its poles developed at $\mathrm{N} \mathrm{S}$, according to the direction of the voltaic influence. If the battery, $\mathrm{Z} \mathrm{C}$, be removed, and the ends of the wire connected with the zinc and copper plates brought into

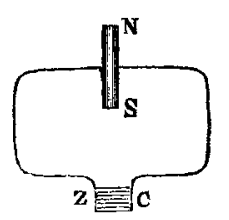
metallic contact, and if the piece of soft iron be again converted into a magnet by means of a permanent horse-shoe magnet, the wire will have the same voltaic state induced on it as it had when connected with the battery.

If a temporary magnet be merely a piece of soft iron having the electricity essentially belonging to it arranged in a particular direction, it is obvious that the motion of the atoms of the electric fluid will take place in the opposite direction when the iron is ceasing to be a magnet or returning to its natural state. Hence the direction of the voltaic influence induced

* See Lond. and Edinb. Phil. Mag., vol, iii. p. 37.-Edrr. 
on the conductor will, as Mr. Faraday has shown, take place in the opposite direction.

2. If two conductors, having electricity induced on them in the same direction by means of an elementary battery, be placed parallel to one another, they will be mutually attracted. Hence, if we remove one of the batteries and connect the ends of the wires as in the first experiment, and then imitate attraction, by making the wires rapidly approach each other in a parallel position, the same electric influence will be induced on the closed circuit as it had when connected with the battery. If the conductors, when connected with the batteries, have their electricities induced in opposite directions, they will mutually repel each other. Hence, if we remove one of the batteries, connect the wires as before, and imitate repulsion, by removing the wires rapidly from each other, the electric influence or current will be induced in the same direction as it was when the wires were connected with the battery.

3. If a voltaic conductor be made to revolve round the pole of a magnet, as in Mr. Faraday's first experiment on rotation, and if the battery be removed and the ends of the conductors brought into metallic contact, the same electric state will be induced on the closed circuit, by turning the wire rapidly round the pole of the magnet by mechanical force.

4. If we produce all the rotations described in works on electro-magnetism, and if we remove the battery, and bring the ends of the conductors into metallic contact, and then continue the rotation by mechanical means, the same electric state will be induced on the conductor which it had when connected with the battery.

In a paper of mine read before the Royal Society on the 21st of March 1833*, I first described the method of making a piece of soft iron or electro-magnet, either straight or in the form of a horse-shoe, revolve rapidly round its centre, either by the action of the earth or of a horse-shoe magnet, by changing its poles troice in every revolution. Hence from the general law it follows, that if the soft iron be made to revolve by mechanical force, the same electric state will be induced on the conductor as it had when the ends of the wires were connected with the battery.

These facts were known, and the experiments publicly exhibited, months before the large revolving electro-magnet was exhibited in the Adelaide Rooms. The general law at which we have arrived may be thus expressed: "If a wire conducting voltaic electricity, produce by its action on magnets or conductors certain motions, as attractions, repulsions, or continued

* See Lond. and Edinb. Phil. Mag., vol, iii. p. 145.-EDrr. 
Prof. Ritchie on the Rotation of closed Voltaic Circuits. 13

rotation; and if the battery be removed, the ends of the wires brought into metallic contact, and the same motions be produced by mechanical means, the conductor will have the same electric state induced on it, as it had when connected roith the battery."

V. On the continued Rotation of a closed Voltaic Circuit, by another closed Circuit. By the Rev. Wildiam Ritchie, LL.D., F.R.S., Professor of Natural and Experimental Philosophy in the Royal Institution of Great Britain, and in the University of London*.

M AMPE'RE has demonstrated that when a closed cirM. cuit (or a conductor of voltaic electricity returning into itself so as to form a complete circuit, ) is acted upon by another closed circuit, there is a determinate position in which stable equilibrium takes place. Hence the impossibility of producing continued rotation by the mutual action of two closed voltaic circuits. Hence also the impossibility of producing continued rotation by the mutual action of two permanent magnets + . But though continued rotation cannot be produced by the action of closed circuits, when the voltaic influence is exerted in a particular direction, I have succeeded in producing such rotation by changing the direction of the voltaic influence; a short account of which may not be unacceptable to the readers of the Philosophical Magazine.

The description of the method will be easiest understood by reference to the annexed figure.

Let A B represent the section of a circular piece of wood, having a groove measuring about an inch in its inner diameter, and half an inch broad, for the purpose of holding mercury. The groove is divided into two compartments by small slips of wood fixed diametrically opposite to one another. 'These compartments may be connected by means of wires with the plates of an elementary battery.

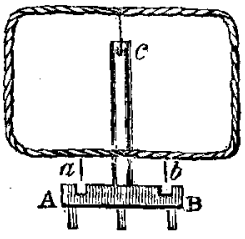
A glass rod, having a small cup, $c$, at the top, is cemented into the centre of the sole of the apparatus. A fine copper wire, covered with silk, is formed into a rectangular coil or closed circuit, as in the figure, the ends of which, $a b$, dip into the mercury contained in the compartments. The lower horizontal branch of the rectangle has the wires separated so

* Communicated by the Author.

+ This property was not known a few years ago, and hence an ingenious Scotch shoemaker contrived to gull the most eminent philosophers in Scotland, by a pretended perpetual motion, alleged to be produced by the mutual action of magnets. 